\title{
Structure-Function Relationships of Antimicrobial Peptides and Proteins with Respect to Contact Molecules on Pathogen Surfaces
}

\author{
Ruiyan Zhang ${ }^{1,2}$, Thomas Eckert ${ }^{3,4}$, Thomas Lütteke ${ }^{3}$, Stefan Hanstein ${ }^{5}$, Axel Scheidig ${ }^{1}$, \\ Alexandre M. J. J. Bonvin ${ }^{6}$, Nikolay E. Nifantiev ${ }^{7}$, Tibor Kožár ${ }^{8}$, Roland Schauer ${ }^{9}$, \\ Mushira Abdulaziz Enani ${ }^{10}$ and Hans-Christian Siebert ${ }^{2, *}$
}

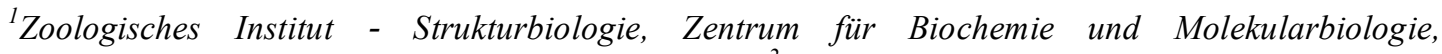
Christian-Albrechts-Universität Kiel, Kiel, Germany; ${ }^{2} R I-B-N T$ - Research Institute of Bioinformatics and Nanotechnology, Kiel, Germany; ${ }^{3}$ Institut fur Veterinärphysiolgie und -Biochemie, Fachbereich Veterinärmedizin, Justus-Liebig-Universität Gießen, Gießen, Germany; ${ }^{4}$ Klinik fur Geburtshilfe, Gynäkologie und Andrologie der Groß- und Kleintiere mit Tierärztlicher Ambulanz, Fachbereich Veterinärmedizin, Justus-Liebig-Universität Gießen, Gießen, Germany; ${ }^{5}$ Geschäftsfeldleitung Biowerkstoffe, Lebensmittel, Fraunhofer-Institut fur Silicatforschung ISC, Projektgruppe fur Wertstoffkreisläufe und Ressourcenstrategie IWKS, Alzenau, Germany; ${ }^{6}$ Bijvoet Center for Biomolecular Research, NMR Spectroscopy, Utrecht University, Utrecht, The Netherlands; ${ }^{7}$ Laboratory of Glycoconjugate Chemistry, Zelinsky Institute of Organic Chemistry, Russian Academy

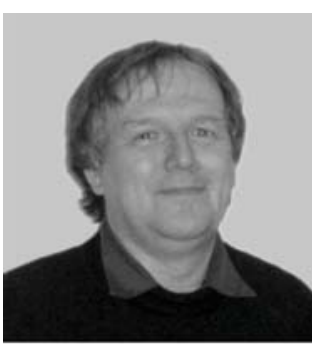

H.-C. Siebert of Sciences, Moscow, Russian Federation; ${ }^{8}$ Centre of Interdisciplinary Biosciences, Pavol Jozef Safarik University in Kosice, Kosice, Slovakia; ${ }^{9}$ Biochemisches Institut, Universitat Kiel, Kiel, Germany; ${ }^{10}$ Infectious Diseases Division, Department of Medicine, King Fahad Medical City, Kingdom of Saudi Arabia
\end{abstract}

\begin{abstract}
The Antimicrobial peptides (e.g. defensins, hevein-like molecules and food-protecting peptides like nisin) are able to interact specifically with contact structures on pathogen surfaces. Besides protein receptors, important recognition points for such contacts are provided by pathogen glycan chains or surface lipids. Therefore, structural data concerning surface exposed glycans and lipids are of the highest clinical interest since these recognition functions play a key role when optimising anti-infection therapies. Approaches in nanomedicine and nanopharmacology in which various biophysical techniques such as NMR (Nuclear Magnetic Resonance), AFM (Atomic Force Microscopy), SPR (Surface Plasmon Resonance) and X-ray crystallography can be combined with biochemical and cell-biological methods will lead to improved antimicrobial peptides by this rational drug design approach. Such a strategy is extremely well suited to support clinical studies focussing on an effective fight against multiresistant pathogens. The data sets which are described here can be considered as universal for the design of various antimicrobial drugs against certain pathogens (bacteria, viruses and fungi) which cause severe diseases in humans and animals. Furthermore, these insights are also helpful for progressing developments in the field of food conservation and food preservation. A detailed analysis of the structure-function relationships between antimicrobial peptides and contact molecules on pathogen surfaces at the sub-molecular level will lead to a higher degree of specificity of antimicrobial peptides.
\end{abstract}

Keywords: Biophysical methods, Nanomedicine, Nanopharmacology, Structure-function relationship.

\section{INTRODUCTION}

Antimicrobial peptides by a strict definition are regarded as small peptides of up to ten amino acid residues with the property of attacking single-cell organisms with pathogenic potential. In a broader definition, peptides/proteins of up to 100 amino acid residues which are able to destroy the pathogenicity of microbes such as bacteria, viruses and fungi can also be included.

Independent of such definitions, the complementarity of structure and function has to be analysed on a nanoscale

*Address correspondence to this author at the RI-B-NT - Research Institute of Bioinformatics and Nanotechnology, Franziusallee 177, 24148 Kiel, Germany; Tel: +49 431880 4353; Fax: +49 431880 4929;

E-mail: hcsiebert@aol.com level with a strategic combination of various biophysical methods in order to obtain detailed information regarding the role of antimicrobial peptides in various diseases. A significant improvement in drug design in different medical fields is an important outcome of such an approach. Furthermore, antimicrobial peptides also play a key role in relation to food preservation and conservation. We will discuss in this article whether certain patterns in the arrangement of amino acids which determine the structural architecture of antimicrobial peptides are characteristic for specific interactions with contact structures (proteins, glycans or lipids) on pathogen surfaces. These recognition molecules are determined by certain functional groups which establish specific interaction processes. Very often the arrangements of functional groups of the contact structures on the pathogen surfaces which are recognised by antimicrobial peptides show a high degree of 
similarity or are even identical with those structures which enable the pathogen to dock to a host cell and spread the infection.

\section{VARIOUS ASPECTS AND CONCLUSIONS}

\subsection{Medical Aspects}

In the study of antimicrobials sialic acids play a prominent role as potential interaction partners since they are the terminal carbohydrate residues of many glycolipids (in this case called gangliosides) and glycan chains from glycoproteins $[1,2]$. N-acetyl neuraminic acid (Neu5Ac) and related molecules (e.g. O-acetylated Neu5Ac moieties) constitute the large family of sialic acids [1]. These molecules are specific and clinically important contact structures for antimicrobial proteins and peptides. Sialic acids on pathogens are therefore a suitable target for a number of antimicrobial peptides. Sialic acids interact e.g. with a small lectin from the Chinese bird hunting spider Selenocosmia huwena Wang (Wang: Chinese expression for King) [3, 4] but are also specific interaction partners for $\alpha$-defensins. The three classes of defensins, $\alpha$-, $\beta$ - and $\theta$-defensins are antimicrobial peptides with three characteristic disulphide bridges and have to be considered as an important part of the innate immune system [5-16]. It can be shown with NMR, SPR and molecular modelling methods that sialic acid residues form stable complexes with HNP1, 2, or 3 (derived from psoriatic skin cells) in a specific way (Fig. 1). For the molecular recognition process, it is very important to which other carbohydrate moiety in a saccharide chain the sialic acid residue is linked and which atoms are involved in the glycosidic linkage. Very often the sialic acid molecule Neu5Ac is alpha 2-3 linked to
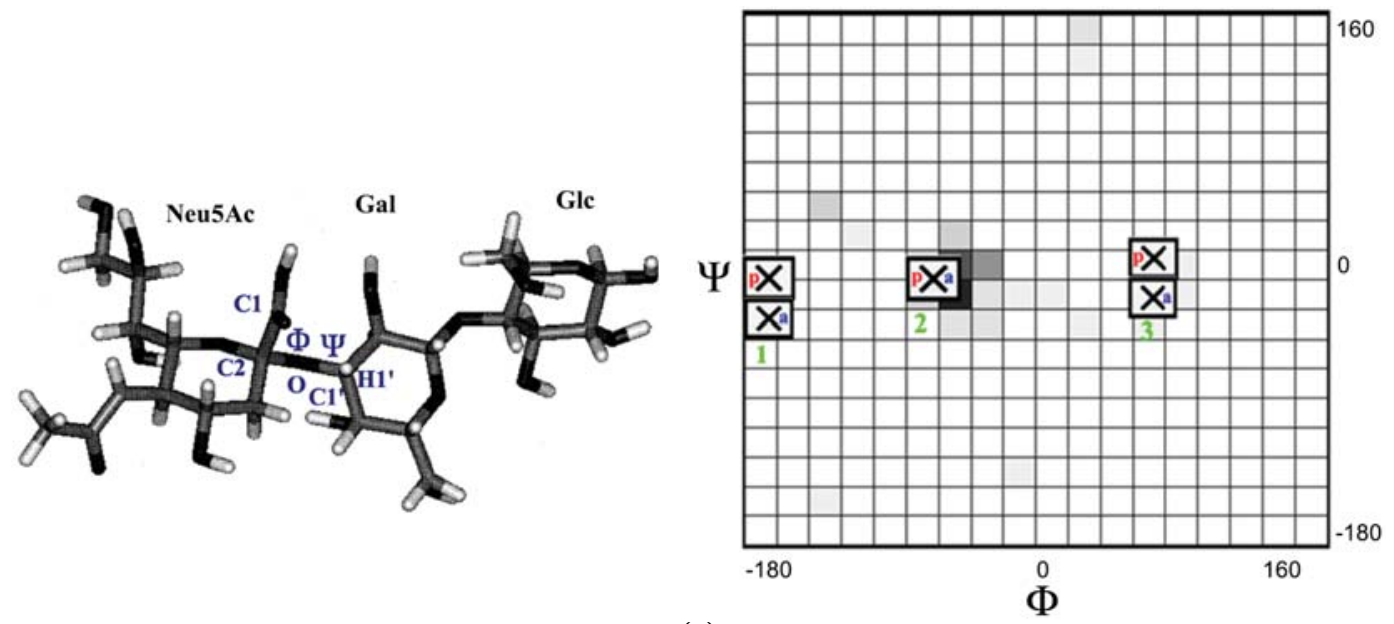

(a)

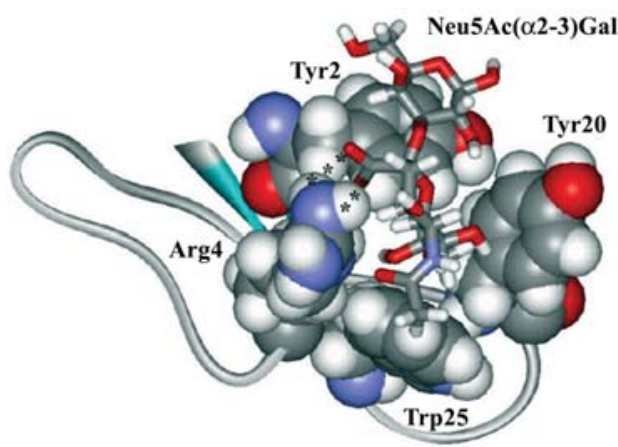

(b)

Fig. (1). a: Quantum chemical calculations of the preferred conformations of the Neu5Ac( $\alpha 2-3)$ Gal linkage using the B3LYB/6-31G* method. The calculations were carried out in the protonated and in the anionic state in order to perform energy minimization under various physical-chemical conditions. In the anionic state the carboxylic groups are calculated without the hydrogen ions. Instead of hydrogen two water molecules have been added. The results from the quantum chemical calculations are combined with data from a $\Phi / \Psi-$ map of this linkage generated with GlyTorsion: www.glycosciences.de/tools/glytorsion/ to compare the calculated values with experimental data.The definition of the glycosidic angles is as follows $\Phi$ : C1-C2-O-C1', $\Psi$ : C2-O-C1'-H1' (C1'and H1'are galactose atoms). The three different energetic local minima of the Neu5Ac( $\alpha 2-3)$ Gal linkage delivered from the data bank are derived from Neu5Ac( $\alpha 2-3)$ Gal linkages in PDB entries. At the positions of minima 1 and 3 we have obtained small differences between the protonated and anionic state concerning the values of the glycosidic angles $\Phi$ and $\Psi$ determined with our quantum chemical methods. The protonated state refers to the crosses with the red letter "p" and the anionic state to the crosses with the blue letter "a". The values of the glycosidic $\Phi$ and $\Psi$ - angle referring to the protonated and to the anionic state only match exactly in the case of minimum 2 . The conformational flexibility of the Gal( $\beta 1-4)$ Glc linkage between galactose and glucose is not considered here. b: HNP2 in complex with a Neu5Ac( $\alpha 2-3) \mathrm{Gal}$ fragment at the energy minimum conformation 2 . The glycosidic angles of the Neu5Ac( $\alpha 2-3)$ Gal linkage are $\Phi:-64^{\circ}$ and $\Psi: 0^{\circ}$ (conformation 2). The important binding-stabilising contact between the carboxylic group of Neu5Ac and Arg4 is highlighted by asterisks. Tyr2, Tyr20 and Trp25 are responsible for stabilisation of the complex mainly by $\pi$-interactions. 
galactose (Gal) (Fig. 1a, top). In this case, the carbon atom 2 of Neu5Ac in its alpha configuration is connected by an oxygen atom with the carbon atom 3 of galactose (Gal). It should be emphasised that this linkage has rotational degrees of freedom and energy minimum conformations (defined by the glycosidic angles $\Phi$ and $\Psi$ ) which can be determined by the biophysical methods described here. These energy minimum conformations of the free state (Fig. 1a, bottom) are selected by receptors as bound state conformations [17-21], for example, as shown for the $\alpha$-defensin HNP1 (Fig. 1b). As demonstrated in Fig. (2a, b, c), atoms of Trp (a), Tyr (b) and Arg (c) residues which occur in the vicinity of Neu5Ac residues (according to Protein Data Bank (PDB) entries at www.pdb.org) are monitored respective to their positions in relation to Neu5Ac and allow a statistical overview (www.glycosciences.de/tools/glytorsion/). For example, it is of special interest which atoms are mainly involved in sialic acid binding. As Fig. (2c) demonstrates, in the case of Arg the interactions with sialic acids are dominated by nitrogen atoms of the amino acid side chain. The $\alpha$-defensins HNP2 and HD5 are canonical examples for sialic acid binding mini-lectins. In order to visualise their binding modes the free and bound state conformations of these antimicrobial peptides are presented in Fig. (3a and b). The HNP2 conformations in the ligand free and in the sialic acid bound state are shown in the three model pictures presented in Fig. (3a). In particular, the comparison between the HNP2 conformation in the ligand-free (Fig. 3a, left, middle) and the sialic acid bound state (Fig. 3a, right) reveals clear differences when focussing on the orientations of the binding relevant amino acid residues Tyr2 Arg4, Tyr20 and Trp25. Conformational differences between the bound state conformations of the human $\alpha$-defensin HD5 in complex with the sialic acid mimicking the tegaserod molecule in its cis- (Fig. $\mathbf{3 b}$, left) or in its trans- (Fig. 3b, right) configuration are also observable. The tegaserod molecules are not displayed in order to visualise their impact on the overall shape of HD5 more clearly. Only the binding-relevant Arg28 residue is marked. Tegaserod is discussed as a polySia glycomimicking molecule with an impact on nerve cell regeneration [22]. Therefore, the conformations of the sialic acid mini-receptor HD5 in its cis- as well as in its trans-tegaserod bound state have been calculated by molecular docking routines within molecular dynamics simulations, and are presented in Fig. (3b). Also in the case of small glycomimicking molecules in their cis- and trans-configurations, a significant conformational impact on HD5 could be calculated with our molecular docking approaches (our own unpublished results, data not shown). When studying lectin SHL-1 from the Chinese birdhunting spider Selenocosmia huwena Wang it turned out that sialic acid specificity is dominated by aromatic amino acid residues as shown in Fig. (3c) [3]. The three tryptophan residues (Trp23, Trp25, Trp32) which are all involved in binding with the polySia disaccharide fragment are labelled. For comparison, a snapshot of a molecular docking study of the $\alpha$-defensin HD5-double mutant (A13R, A32R) with N-acetyl muramic acid (MurNAc), where Arg residues play a crucial role, is presented in Fig. (4). Our molecular docking calculations indicate that the replacement of Ala13 by Arg and Ala 32 by Arg alters the affinity to muramic acid (MurNAc) according to the calculated energy values, which will be published elsewhere. MurNAc is, like Neu5Ac, an acid and Nacetylated carbohydrate. It is part of a biopolymer in the bacterial cell wall, built from alternating units of $\mathrm{N}$ acetylglucosamine (GlcNAc) and $\mathrm{N}$-acetylmuramic acid (MurNAc), cross-linked with oligopeptides at the lactic acid residue of MurNAc. This layered structure is called peptidoglycan murein.

\subsection{Nutritional Aspects}

Antimicrobial peptides are also of highest importance when new concepts in the field of food preservation are needed. The molecular interplay of certain peptides already serve as such agents, can be taken as starting point for these concepts. The N-terminal part of nisin (Fig. 5, crucial residues between 1-12 are shown in a surface representation) encages the pyrophosphate moiety of the pathogen surface lipid 3LII, e.g. the gram-positive methicillin-resistant Staphylococcus aureus (MRSA) [23, 24]. The side chains of these nisin residues are labelled in different colours. The $\mathrm{N}$-acetyl muramic acid (MurNAc) moiety, which occurs on the surface on many bacteria forms stable complexes with nisin. This moiety, the pyrophosphate part, and the first isoprene unit of 3LII fit in the binding pocket of nisin (Fig. 5). In this case the carbohydrate and the fatty part of the pathogen lipid 3LII both contribute to the stable 3LII nisin complex. The antimicrobial activity of nisin against the pathogen depends therefore on the specific contact with the surface lipid 3LII. Other instructive examples of food-
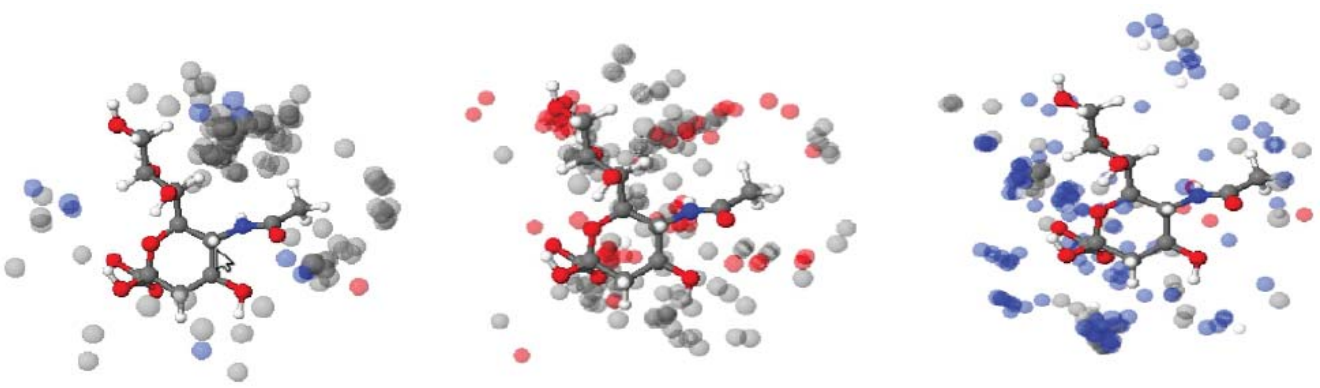

Fig. (2). Atoms of Trp (left), Tyr (middle) and Arg (right) residues occurring around Neu5Ac residues according to pdb-entries and an evaluation with the GlyVicinity program [82]. In order to avoid redundancies in respect of similar structures in the protein data bank a $90 \%$ clustering filter was used [82]. This presentation allows a statistical evaluation to figure out which functional groups of Neu5Ac and Trp (a), Tyr (b) or Arg (c) residues are interacting with each other. The atoms of these three amino acid residues which occur in the vicinity of Neu5Ac can be discriminated by their colour: carbon: grey, nitrogen: blue, oxygen: red, hydrogen: white. 

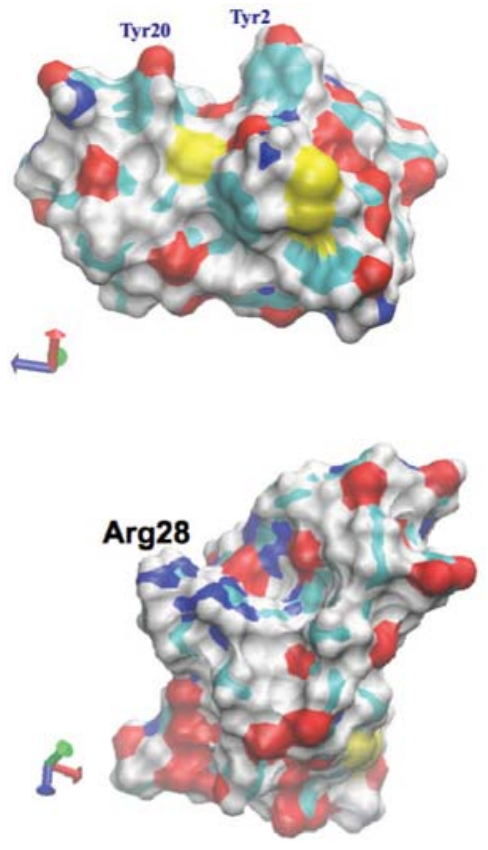
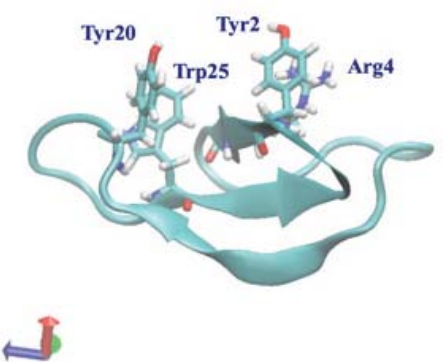

(a)

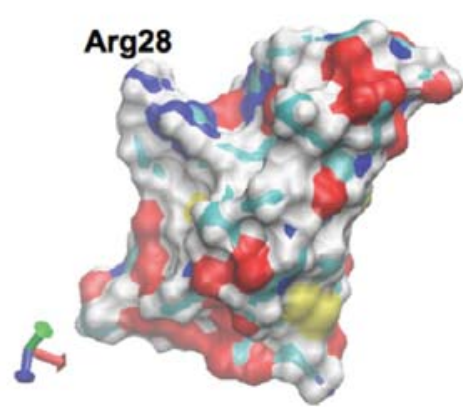

(b)
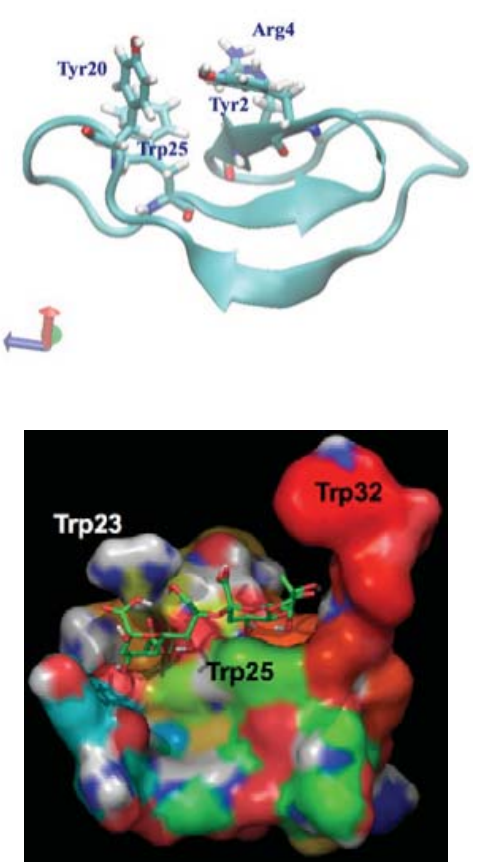

(c)

Fig. (3). a: HNP2 conformations in the ligand-free (left, middle) and in the sialic acid bound state (right). The conformational differences can clearly be observed when the orientations of the relevant binding amino acid residues Tyr2, Arg4, Tyr20 and Trp25 are compared. Especially, when comparing the orientations of Tyr2 and Arg4 (middle vs. right picture) their turns to the carbohydrate binding pocket in the ligandbound state are obvious. b: HD5 conformations (based on X-ray crystallographic data [15]) in the bound state of the sialic acid mimicking molecule tegaserod in its cis (left) or in its trans (right) configuration. The tegaserod molecules are not displayed in order to visualise their impact on the overall shape of HD5 more clearly. The binding-relevant Arg28 residue of HD5 is marked. c: Surface representation of the lectin SHL-1 from the Chinese bird-hunting spider Selenocosmia huwena Wang in complex with a polySia disaccharide fragment. Three tryptophan residues (Trp23, Trp25, Trp32) are labelled, which all are involved in ligand binding. The image shows the shape of a sialic acid binding pocket in the length of two disaccharide units. In contrast to tryptophan residues Trp23 and Trp25, which are essential for complex formation, the Trp32 residue stabilises the complex, but is not essential for specific ligand binding.

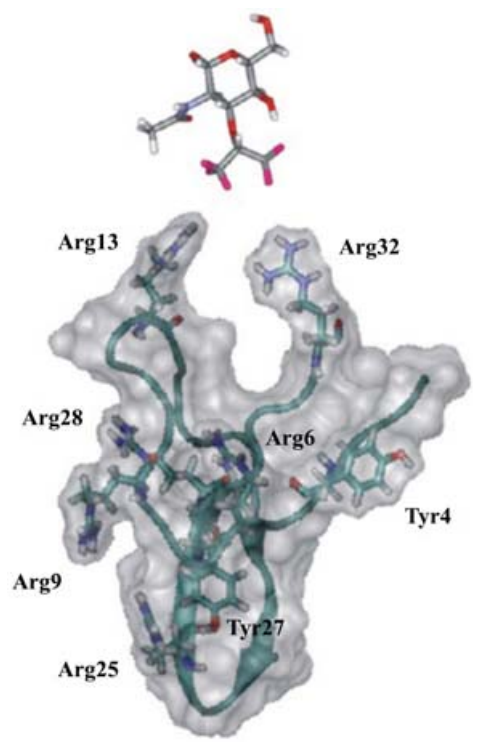

Fig. (4). Docking study of the defensin HD5-double mutant (A13R, A32R) and N-acetyl muramic acid (MurNAc). The replacement of Ala13 by Arg and Ala 32 by Arg lowers the affinity to MurNAc according to the docking simulation. Such exchanges of amino acids have led to the conclusion that Arg28 is an essential residue for specific carbohydrate interaction processes.

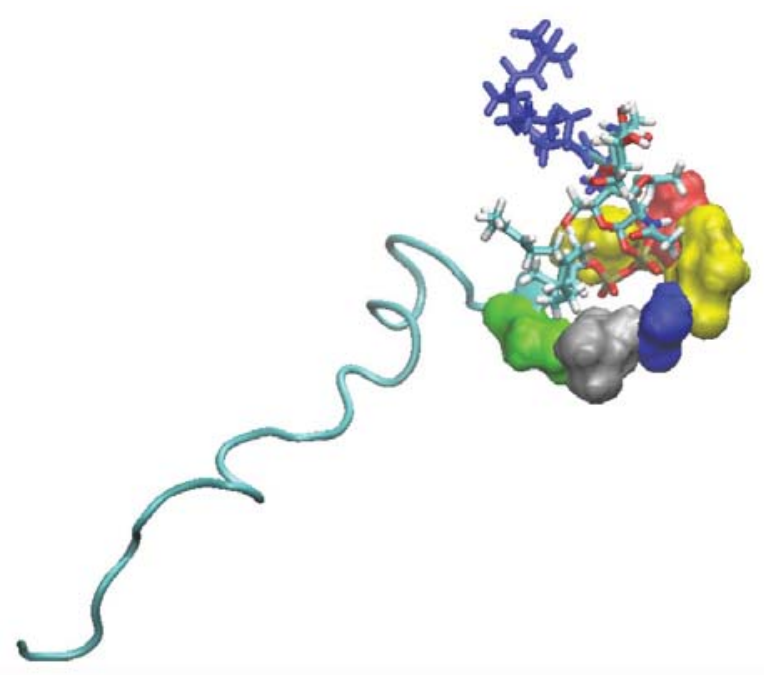

Fig. (5). Nisin structure (1WCO.pdb). The amino acid residues which are essential for carbohydrate (MurNAc) binding are shown in the surface representation. Ile1 and Ile4: yellow, Dhb2: red, Dha5: blue, Leu6: silver, Pro9: green, (Dha: Dehydroalanine, Dhb: Dehydrobutyrine). The blue stick model consists of five residues with a Lys in the middle. 
protecting peptides are lactoferrin fragments. Lactoferrin is a carbohydrate binding glycoprotein and an effective antimicrobial peptide in milk. The X-ray derived structure of this glycoprotein in complex with a trisaccharide (2DP8.pdb) is shown in Fig. (6), top. A structural model of bovine lactoferrin (1BLF.pdb) with the highlighted ferrampin sequence is displayed in Fig. (6), bottom. Besides lactoferrampin, the peptide lactoferricin is a further lactoferrin-derived antimicrobial peptide. Lactoferricin is an amphipathic, cationic peptide with antimicrobial and anti-cancer properties. It can be generated by a pepsin-mediated digestion of lactoferrin. Lactoferricin is the most studied antimicrobial peptide derived from milk proteins. The complete sequence of lactoferricin (FKCRRWQWRMKKLGAPSITCVRRAF) corresponds to the lactoferrin fragment of residues 17-41. The sequence of lactoferricin is present in the antimicrobial lactoferrin fragment (1LFC.pdb) shown in Fig. (7) as stick (top) and space filling (bottom) models. This peptide interacts with the lipid part of the pathogen, e.g. MRSA [25, 26]. Furthermore, the already mentioned defensins also play a crucial
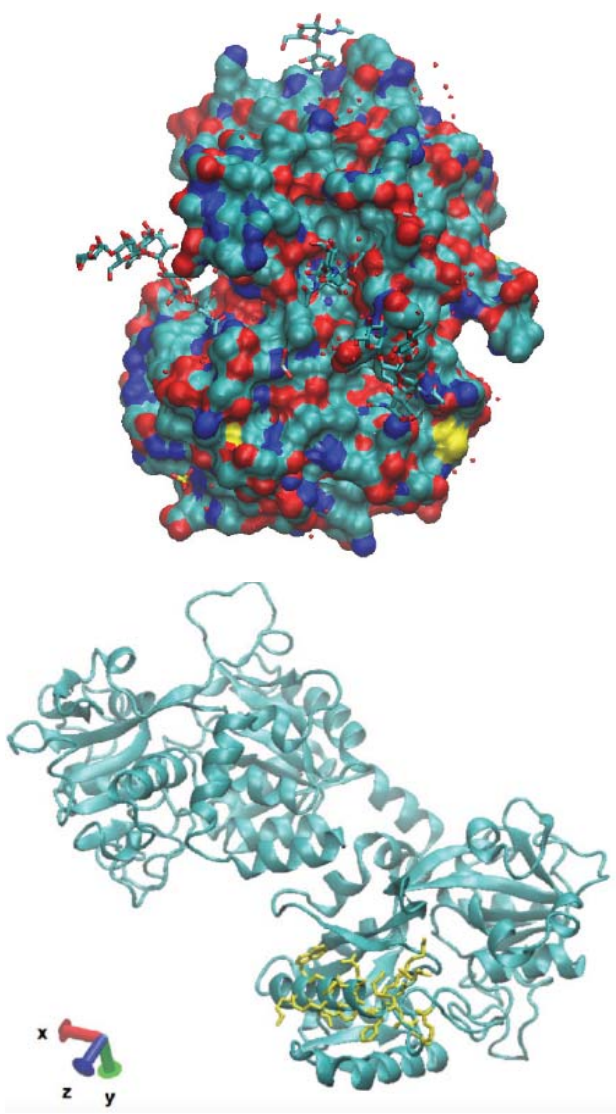

Fig. (6). Surface presentation of the glycoprotein lactoferrin from Bos taurus in complex with a trisaccharide (2DP8.pdb) - top [PDB: Singh N.; Sharma S.; Singh T. P. - to be published]. The covalently bound glycochain fragments and the trisaccharide ligand are displayed as stick models. Backbone representation of Bos taurus lactoferrin (1BLF.pdb) - bottom [25]. The ferrampin sequence is highlighted in yellow: WKLLSKAQEKFGKNKSR (W268 to R284) [26]. This lactoferrin fragment permeabilises the outer membrane of gram-negative bacteria and neutralises endotoxins. The three perpendicular oriented arrows are stretching the $\mathrm{x}, \mathrm{y}, \mathrm{z}$ coordinate system $[80,81]$. role in food preservation and are in some cases important for the survival of certain animals. For example, for male king penguins (Aptenodytes patagonicus) it is feasible to preserve undigested food in their stomach for several weeks during the last part of egg incubation. This ensures survival of the newly hatched chick, in cases where the return of the female penguin from the sea is delayed. It is described in the literature that a 38-residue antimicrobial peptide named spheniscin which belongs to the $\beta$-defensin subfamily is mainly responsible for the food preservation properties in the stomach of male king penguins [12, 27]. The spheniscin concentration was found to strongly increase during the period of food storage. It could be shown that this peptide has a broad antimicrobial activity spectrum, affecting the growth of both pathogenic bacteria and fungi. When highlighting the two aromatic residues Phe19 and Trp38 it is obvious how the positions of the two contact residues alter when comparing four NMR minimum conformations with each other (Fig. 8ad). These observations are of special interest when potential target structures have to be analysed aiming at new strategies in food protection.

\subsection{Animal Health Care-Medical and Nutritional As- pects}

An actual example in respect of the need for new potent antimicrobial peptides is respiratory infection caused by
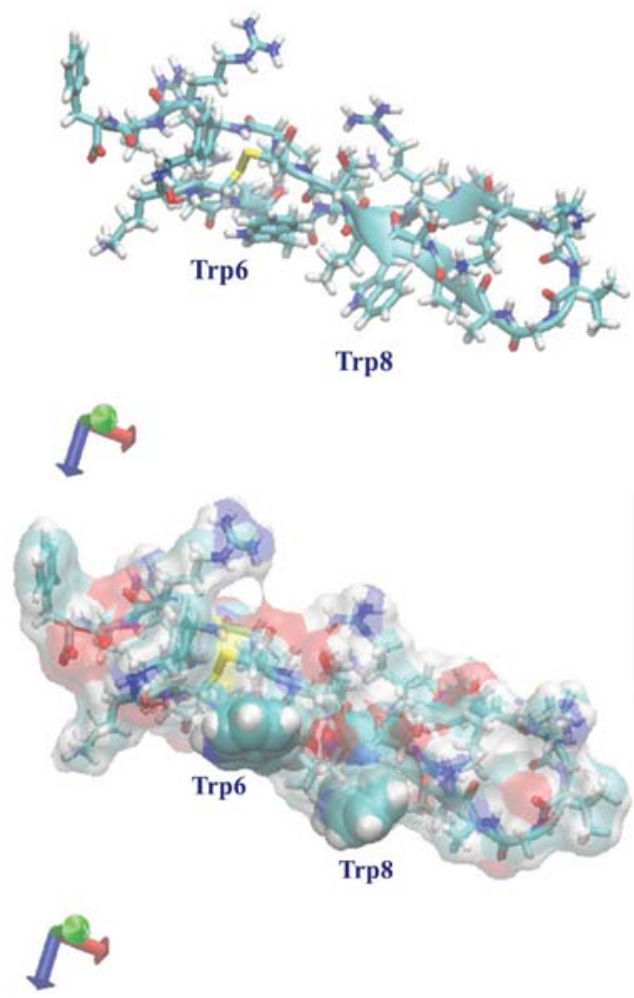

Fig. (7). Lactoferricin (1LFC.pdb) [83] in a stick (top) and in a space-filling surface (bottom) representation. The Trp residues 6 and 8 of this membrane interacting peptide are labelled. Lactoferricin consists in total of 25 amino acid residues: FKCRRWQWRMKKLGAPSITCVRRAF. The three perpendicular oriented arrows which are stretching the $\mathrm{x}, \mathrm{y}, \mathrm{z}$ coordinate system are orientated identically in respect to the model representations at the top and at the bottom. 
Middle East Respiratory Syndrome corona viruses (MERS$\mathrm{CoV})$. The viral spike $\mathrm{S}$ glycoprotein is responsible for mediating receptor binding and membrane fusion. Recent studies have proposed that the carboxyl terminal portion (S2 subunit) of the $\mathrm{S}$ protein is a class I viral fusion protein (Fig. 9). This structure (2RUM.pdb) of the related Severe Acute Respiratory Syndrome corona viruses (SARS-CoV) [28] interacts with the lipid part of the host cell membranes. Potential strategies against SARS-CoV and MERS-CoV, as well as the inhibition of the carbohydrate-protein-interaction, also include blocking-strategies which prevent a docking of the virus to lipid parts of the host cell membranes. In this context the lipid fusion peptide is of special interest. Biophysical methods such as Nuclear Magnetic Resonance (NMR) and Atomic Force Microscopy (AFM) as well as molecular modelling can be used to improve antiviral strategies. A sophisticated NMR technique which is known as the laser photo Chemically Induced Nuclear Polarisaton (CIDNP) method can be applied for a receptor - ligand analysis [29-31] if Tyr- and Trp-residues are surface exposed. The virus fusion peptide shown in five energy minimum conformations in Fig. (9) has two CIDNP sensitive amino acid residues which are always surface-exposed in the receptor-unbound state: Trp2 and Tyr9. It is therefore possible to establish these two residues as special sensors when specially designed fusion peptides are tested to block the contact with the virus. These interaction studies can be carried out with model membranes in NMR tubes. Possible modifications of these fusion peptides are the addition of certain amino acid residues and/or the introduction of special

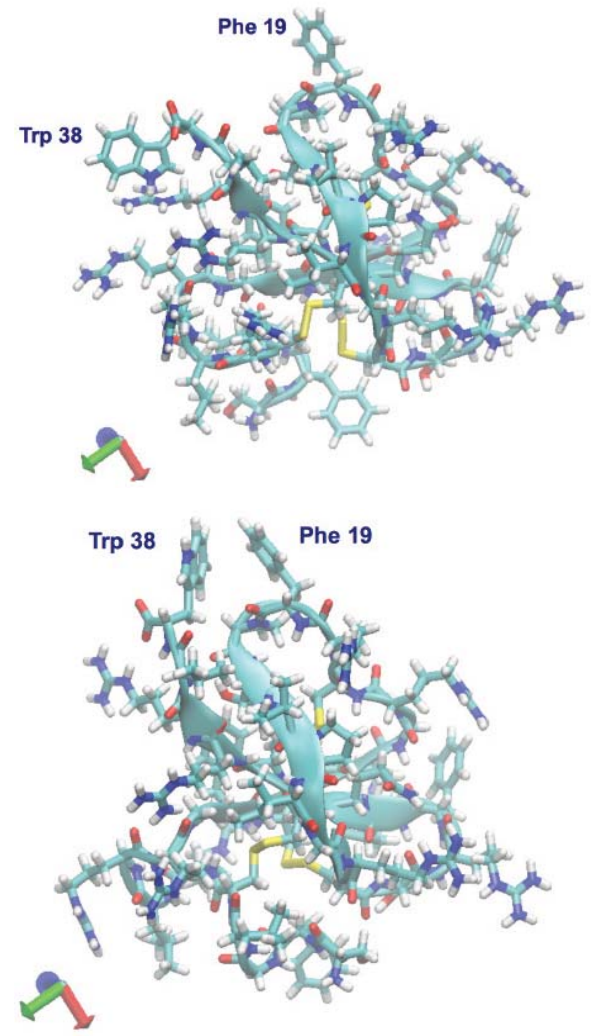

functional groups. Beside structural properties, the interaction dynamics have to be taken under account. As the flexibility of the CIDNP sensitive Trp38 residue in the $\beta$-defensin spheniscin suggests (Fig. 8) this special NMR method is also extremely suitable when the surface accessibilities of $\alpha$ - and $\beta$-defensins, hevein-like molecules or other mini-lectins are analysed in the absence and in the presence of various ligands [3, 12, 15, 28, 29]. In the case where potent new antimicrobial peptides have to be designed it is also important to focus on low mammalian cell toxicity and suitable model membrane systems $[32,33]$. Nature itself provides a number of blueprints for this purpose. Cyclic defensins can be considered as such examples. Theta-defensins ( $\theta$-defensins) also called retrocyclins are a family of mammalian antimicrobial cyclic peptides which are found in ,old world” primates, but not in humans, gorillas, bonobos, or chimpanzees. This defensin sub-family consists of a pair of antiparallel $\beta$-sheets linked by three disulphide bonds arranged as a ladder along the sheets to form an extremely stable structure. Depending on the $\mathrm{pH}$ value, $\theta$-defensins have a tendency to selfassociate into trimers. In contrast to $\alpha$ - and $\beta$-defensins the $\theta$ defensins have no aromatic amino acid residues, which are important for carbohydrate interactions. However, these cyclic antimicrobial peptides are rich in arginine (Arg) residues, which are also crucial moieties when specific peptide/ protein - carbohydrate interactions are taking place (Fig. 1b, Fig. 2c, Fig. 4). Therefore, the antimicrobial $\theta$-defensins should not be underestimated as proper scaffolds for peptidebased drug design [34].

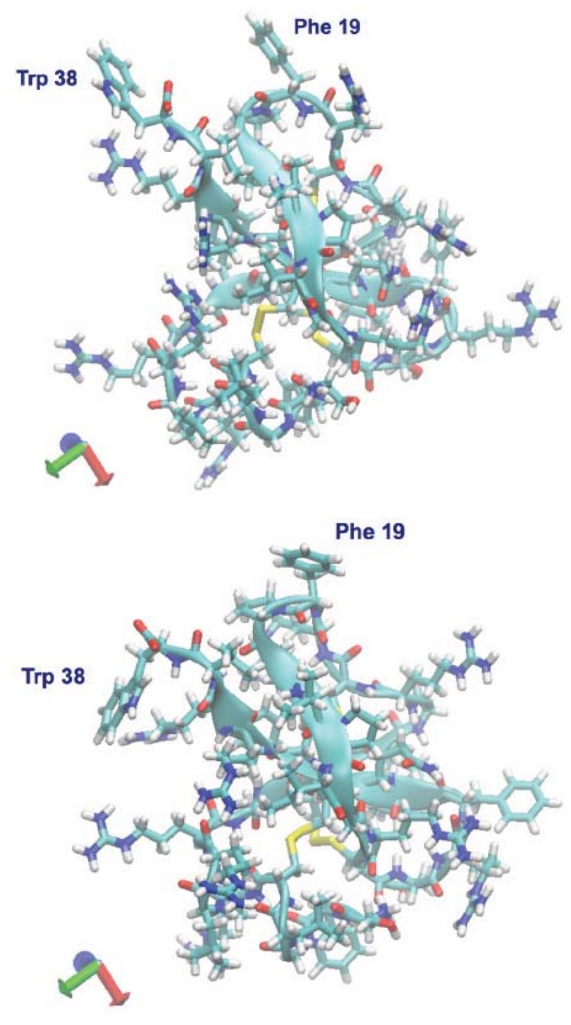

Fig. (8). Four NMR energy minimum structures of spheniscin (1UT3.pdb) [12], a $\beta$-defensin from the stomach of male king penguins (Aptenodytes patagonicus). The aromatic amino acids Phe19 and Trp38 with potential pathogen specificity are highlighted. A comparison with chicken ovodefensin has recently been described in the literature [84]. 

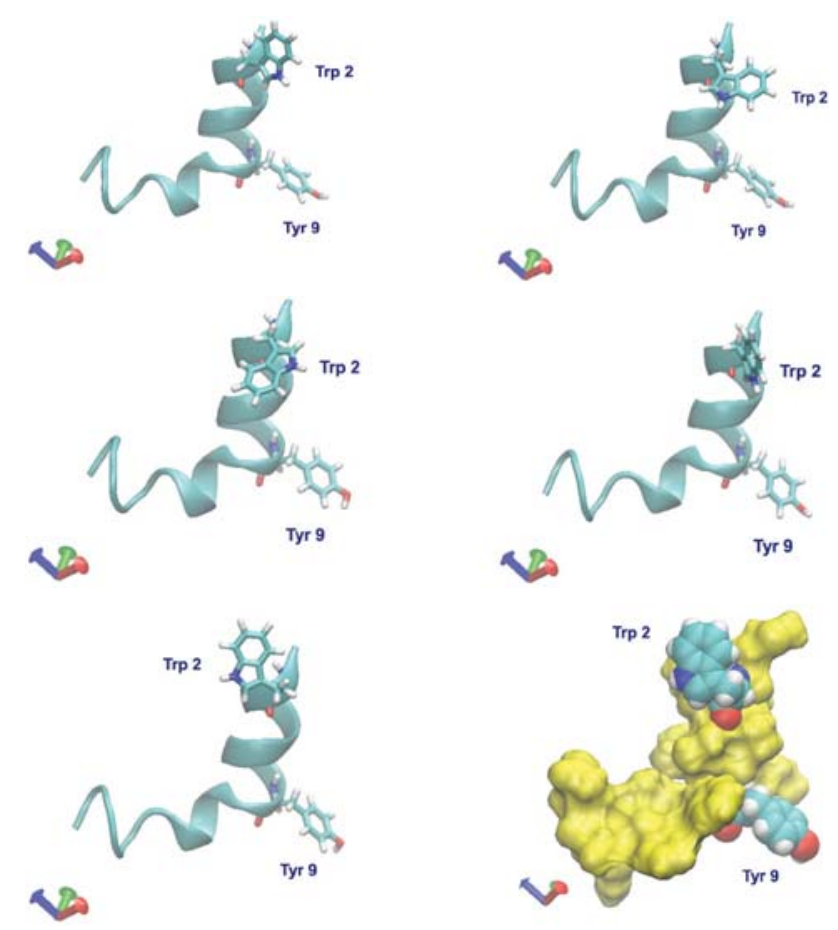

Fig. (9). SARS-CoV fusion peptide (2RUM.pdb) [PDB: Mahajan M.; Bhattacharjya S. - to be published]. Five NMR structures in which the backbone and the amino acid residues Trp2 and Tyr9 are shown, thereby focussing on the different conformations of the aromatic amino acid residues. The space-filling structure corresponds to the fifth NMR structure shown as stick model at the bottom on the left side. In this picture six at the bottom on the right side, the residues 1, 3-8 and 9-17 are displayed in the yellow surface representation. Residues 2 and 9 are shown in a van-der-Waals representation. This antimicrobial peptide which interacts directly with membrane lipids can be studied with laser photo CIDNP NMR methods in the absence and in the presence of membrane fragments.

\section{CONCLUSION}

Significant advances in the design of antimicrobial peptides can be expected when suitable model systems are analysed with state-of-the-art biophysical techniques. When studying hevein-domains [35-39] and their interactions with ligand structures on the nanoscale level, it turned out that certain amino acid residues play a dominant role if carbohydrates are bound in a specific way to the receptor structure. Besides the aromatic Tyr and Trp residues, Arg is a crucial building brick which stabilises glycan-protein complexes. However, the optimal strategy to hinder the pathogen attack, strongly depends on the particular disease [40-45]. Minilectins such as the sialic acid binding spider lectin SHL-1 and several defensins are able to interact specifically with sialic acid containing carbohydrate chains, which are characteristic for various infections. In the case of antimicrobial peptides which target contact structures on pathogen surfaces (e.g. Neu5Ac), further improvements are especially needed, because several multiresistant bacterial strains exist. The necessary therapeutic improvements concerning the antimicrobial effects of peptides will be provided by rational modifications of structural properties in respect to binding strength and specificity. This will support anti-infective therapies against bacteria, viruses and fungi significantly, including the important aspect of anti-inflammation. A combination of biophysical techniques and bioinformaticsderived tools with biochemical and cell biological methods allows the generation of new drugs which are effective against dangerous pathogens, e.g. gram-negative Klebsiella pneumoniae [46-48]. Beside viral and bacterial infections, fungi as severe pathogens should not be forgotten [49]. Defensins are also described in respect of their antifungal properties [50] and are therefore proper candidates for such therapeutic approaches. As well as sialic acids being crucial contact structures in bacteria or virus - host cell interaction processes they also play a similar important role when fungi cause health problems as pathogens [51, 52]. Therefore, antimicrobial peptides with a specificity for sialic acids are of great relevance in clinical approaches directed against fungal diseases. When studying the interactions between pathogens and host cells intensely on a nanoscale level not only the specific binding processes between antimicrobial peptides and carbohydrate chains have to be considered. Also proteinand lipid-contact structures are crucial interaction partners for antimicrobial peptides. Since all three classes of biomolecules have to be taken into account, being the Achilles heel of a pathogen, nanomedical and nanopharmacological approaches must focus on characteristic molecular recognition points including conformational aspects on the ligand and on the receptor side [53-60]. Such recognition points are, for example, distinct functional groups of carbohydrate residues (such as O-acetyl groups) or sulphate groups interacting with certain amino acid residues of antimicrobial peptides. Both cyclic and linear peptides $[54,55]$ have to be taken into account as antimicrobial molecules. Taking these approaches, improved strategies for food preservation in the field of applied health care will also be achieved. Further developments in the field of antimicrobial peptide design can be expected when these molecules are analysed in a similar way as for the structure-function relationships of bio-active 
collagen-fragments [61-65]. From a purely structural point of view, antimicrobial peptides are diverse, however, when suitable model systems [66-73] are analysed with nanomedical and nanopharmacological emphasis, results of general validity can be expected. Addressing the question whether antimicrobial peptides can interact with carbohydrate or lipid components on pathogen surfaces [74-79] it is possible to optimise drug design approaches against multiresistant pathogens (e.g. against vancomycin resistant Staphylococcus aureus strains). Such promising nanomedical and nanopharmacological developments can also be expected in other clinical fields such as oncology and neuronal regeneration, thereby, shortening the route from "bench to clinical bedside".

\section{CONFLICT OF INTEREST}

The authors confirm that this article content has no conflict of interest.

\section{ACKNOWLEDGEMENTS}

We thank our colleagues Jens-Michael Schröder, Daron Freedberg, Bob Lehrer and Wuyuan Lu for many fruitful discussions about antimicrobial peptides and their contact structures on pathogen surfaces. NEN is supported by RSF grant 14-23-00199.

\section{REFERENCES}

[1] Schauer, R. Sialic acids: fascinating sugars in higher animals and man. Zoology (Jena), 2004, 107, 49-64.

[2] Severi, E.; Hood, D. W.; Thomas, G. H. Sialic acid utilization by bacterial pathogens. Microbiology, 2007, 153, 2817-2822.

[3] Siebert, H.-C.; Lu, S.-Y.; Wechselberger, R.; Born, K.; Eckert, T.; Liang, S.; von der Lieth, C.-W.; Jiménez-Barbero, J.; Schauer, R.; Vliegenthart, J. F. G.; Lütteke, T.; André, S.; Kaltner, H.; Gabius, H.-J.; Kožár, T. A lectin from the Chinese bird-hunting spider binds sialic acids. Carbohydr. Res., 2009, 344, 1515-1525.

[4] Liang, S. An overview of peptide toxins from the venom of the Chinese bird spider Selenocosmia huwena Wang [= Ornithoctonus huwena (Wang)]. Toxicon, 2004, 43, 575-585.

[5] Ding, L.; Yang, L.; Weiss, T. M.; Waring, A. J.; Lehrer, R. I.; Huang, H. W. Interaction of antimicrobial peptides with lipopolysaccharides. Biochemistry, 2003, 42, 12251-12259.

[6] Wei, G.; de Leeuw, E.; Pazgier, M.; Yuan, W.; Zou, G.; Wang, J.; Ericksen, B.; Lu, W.-Y.; Lehrer, R. I.; Lu, W. Through the looking glass, mechanistic insights from enantiomeric human defensins. $J$. Biol. Chem., 2009, 284, 29180-29192.

[7] Nguyen, T. X.; Cole, A. M.; Lehrer, R. I. Evolution of primate $\theta-$ defensins: a serpentine path to a sweet tooth. Peptides, 2003, 24, 1647-1654.

[8] Cole, A. M.; Hong, T.; Boo, L. M.; Nguyen, T.; Zhao, C.; Bristol, G.; Zack, J. A.; Waring, A. J.; Yang, O. O.; Lehrer, R. I. Retrocyclin: a primate peptide that protects cells from infection by Tand M-tropic strains of HIV-1. Proc. Natl. Acad. Sci. USA, 2002, 99, 1813-1818.

[9] Lehrer, R. I. Primate defensins. Nat. Rev. Microbiol., 2004, 2, 727738.

[10] Ganz, T. Defensins: antimicrobial peptides of innate immunity. Nat. Rev. Immunol., 2003, 3, 710-720.

[11] Zasloff, M. Antimicrobial peptides of multicellular organisms. Nature, 2002, 415, 389-395.

[12] Landon, C.; Thouzeau, C.; Labbé, H.; Bulet, P.; Vovelle, F. Solution structure of spheniscin, a â-defensin from the penguin stomach. 2004, 279, 30433-30439.

[13] Lehrer, R. I.; Lu, W. $\alpha$-Defensins in human innate immunity. Immunol Rev., 2012, 245, 84-112.

[14] Lehrer, R. I.; Jung, G.; Ruchala, P.; Wang, W.; Micewicz, E. D.; Waring, A. J.; Gillespie, E. J.; Bradley, K. A.; Ratner, A. J.; Rest,
R. F.; Lu, W. Human $\alpha$-defensins inhibit hemolysis mediated by cholesterol-dependent cytolysins Infect. Immun., 2009, 77, 40284040.

[15] Szyk, A.; Wu, Z.; Tucker, K.; Yang, D.; Lu, W.; Lubkowski, J. Crystal structures of human $\alpha$ - defensins HNP4. HD5, and HD6. Protein Sci., 2006, 15, 2749-2760.

[16] Lehrer, R. I.; Jung, G.; Ruchala, P.: André, S.; Gabius, H.-J.; Lu, $\mathrm{W}$. Multivalent binding of carbohydrates by the human $\alpha$-defensin, HD5. J. Immunol., 2009, 183, 480-490.

[17] Siebert, H.-C.; Reuter, G.; Schauer, R.; von der Lieth, C. W.; Dabrowski, J. Solution conformation of $\mathrm{GM}_{3}$ gangliosides containing different sialic acid residues as revealed by NOE based distance mapping, molecular mechanics, and molecular dynamics calculations. Biochemistry, 1992, 31, 6962-6971.

[18] Siebert, H.-C.; André, S.; Lu, S.-Y.; Frank, M.; Kaltner, H.; van Kuik, J. A.; Korchagina, E. Y.; Bovin, N.; Tajkhorshid, E.; Kaptein, R.; Vliegenthart, J. F. G.; von der Lieth, C.-W.; JiménezBarbero, J.; Kopitz, J.; Gabius, H.-J. Unique conformer selection of the human growth-regulatory lectin galectin-1 for ganglioside $\mathrm{GM}_{1}$ versus bacterial toxins. Biochemistry, 2003, 42, 14762-14773.

[19] André, S.; Kaltner, H.; Lensch, M.; Russwurm, R.; Siebert, H.-C.; Tajkhorshid, E.; Heck, A. J. R. M.; von Knebel-Doeberitz, Gabius, H.-J.; Kopitz, J. Determination of structural and functional overlap/divergence of five proto-type galectins by analysis of the growth-regulatory interaction with ganglioside $\mathrm{GM}_{1}$ in silico and in vitro human neuroblastoma cells. Int. J. Cancer, 2005, 114, 46-57.

[20] Siebert, H.-C.; Rosen, J.; Seyrek, K.; Kaltner, H.; André, S.; Bovin, N. V.; Nyholm, P.-G.; Sinowatz, F.; Gabius, H.-J. alpha2,3/alpha2,6-Sialylation of N-glycans: non-synonymous signals with marked developmental regulation in bovine reproductive tracts. Biochimie, 2006, 88, 399-410.

[21] Siebert, H.-C.; Born, K.; André, S.; Frank, M.; Kaltner, H.; von der Lieth, C.-W.; Heck, A. J. R.; Jiménez-Barbero, J.; Kopitz, J.; Gabius H.-J.; Carbohydrate chain of ganglioside $\mathrm{GM}_{1}$ as a ligand: identification of the binding strategies of three 15 mer peptides and their divergence from the binding modes of growth-regulatory galectin-1 and cholera toxin. Chem. Eur. J., 2006, 12, 388-402.

[22] Bushman, J.; Mishra, B.; Ezra, M. M.; Gul, S.; Schulze, C.; Chaudhury, S.; Ripoll, D.; Wallqvist, A.; Kohn, J.; Schachner, M.; Loers, G. Tegaserod mimics the neurostimulatory glycan polysialic acid and promotes nervous system repair. Neuropharmacology, 2014, 79, 456-466.

[23] Hsu, S.-T.D.; Breukink, E.; Tischenko, E.; Lutters, M. A. G.; De Kruijff, B.; Kaptein, R.; Bonvin, A. M. J. J.; van Nuland, N. A. J. The nisin-lipid II complex reveals a pyrophosphate cage that provides a blueprint for novel antibiotics. Nat. Struct. Mol. Biol., 2004, 11, 963-967.

[24] Hsu S. T.; Breukink E.; de Kruijff B.; Kaptein R.; Bonvin A. M. J. J.; van Nuland, N. A. J. Mapping the targeted membrane pore formation mechanism by solution NMR: the nisin Z and lipid II interaction in SDS micelles. Biochemistry, 2002, 41, 7670-7676.

[25] Moore, S. A.; Anderson, B. F., Groom, C. R.; Haridas, M.; Baker, E. N. Three-dimensional structure of diferric bovine lactoferrin at $2.8 \AA$ Åresolution. J. Mol. Biol., 1997, 274, 222-236.

[26] Ghosh, A.; Datta, A.; Jana, J.; Kar, R. K.; Chatterjee, C.; Chatterjee, S.; Bhunia, A. Sequence context induced antimicrobial activity: insight into lipopolysaccharide permeabilization. Mol. BioSyst., 2014, 10, 1596-1612.

[27] Thouzeau, C.; Le Maho, Y.; Froget, G.; Sabatier, L.; Le Bohec, C.; Hoffmann, J. A.; Bulet, P. Spheniscins, avian $\beta$-defensins in preserved stomach contents of the king penguin, Aptenodytes patagonicus. J. Biol. Chem., 2003, 278, 51053-51058.

[28] Mahajan, M.; Bhattacharjya, S. NMR structures and localization of the potential fusion peptides and the pre-transmembrane region of SARS-CoV: Implications in membrane fusion. Biochim. Biophys. Acta, 2015, 1848, 721-730.

[29] Siebert, H.-C.; von der Lieth, C.-W.; Kaptein, R.; Beintema, J. J.; Dijkstra, K.; Nuland, N.; Soedjanaatmadja, U. M. S.; Rice, A.; Vliegenthart, J. F. G.; Wright, C. S.; Gabius, H.-J. Role of aromatic amino acids in carbohydrate binding of plant lectins. Laser photo CIDNP (chemically induced dynamic nuclear polarization) study of hevein domain-containing lectins. Proteins, 1997, 28, 268-284.

[30] Siebert, H.-C.; Adar, R.; Arango, R.; Burchert, M.; Kaltner, H.; Kayser, G.; Tajkhorshid, E.; von der Lieth, C.-W.; Kaptein, R.; Sharon, N.; Vliegenthart, J. F. G.; Gabius, H.-J. Involvement of laser photo CIDNP (chemically induced dynamic nuclear polariza- 
tion) - reactive amino acid side chains in ligand binding by galactoside-specific lectins in solution. Similarities in the role of tryptophan/ tyrosine residues for ligand binding between a plant agglutinin and mammalian/avian galectins and the detection of an influence of single-site mutagenesis on surface presentation of spatially separated residues. Eur. J. Biochem., 1997, 249, 27-38.

[31] Gabius, H.-J.; Siebert, H.-C.; André, S.; Jiménez-Barbero, J.; Rü diger, H. Chemical biology of the sugar code. ChemBioChem, 2004, 5, 740-764.

[32] Chai, H.; Allen, W. E.; Hicks, R. P. Spectroscopic investigations of the binding mechanisms between antimicrobial peptides and membrane models of Pseudomonas aeruginosa and Klebsiella pneumoniae. Bioorg. Med. Chem., 2014, 22, 4210-4222.

[33] Javadpour, M. M.; Juban, M. M.; J. Lo, W.-C.; Bishop, S. M.; Alberty, J. B.; Cowell, S. M.; Becker, C. L.; McLaughlin, M. L. De novo antimicrobial peptides with low mammalian cell toxicity. $J$. Med. Chem., 1996, 39, 3107-3113.

[34] Conibear, A.; Craik, D. The chemistry and biology of theta defensins. Angew. Chem., (Intern. ed.), 2014, 53, 10612-10623.

[35] Jiménez-Barbero, J.; Cañada, F. J.; Asensio, J. L.; Aboitz, N.; Vidal, P.; Canales, M. A.; Gabius, H.-J.; Siebert, H.-C. Heveindomains: an attractive model to study carbohydrate-protein interactions at atomic resolution. Adv. Carbohydr. Chem. Biochem., 2006, 60, 303-354

[36] Asensio, J. L.; Cañada, F. J.; Siebert, H.-C.; Laynez, J.; Poveda, A.; Nieto, P. M.; Soedjanaatmadja, U. M.; Gabius, H.-J.; JiménezBarbero, J. Structural basis for chitin recognition by defense proteins of plants: GlcNAc residues are bound in a multivalent fashion by extended binding sites in hevein domains. Chem. Biol., 2000, 7, 529-543.

[37] Asensio, J. L.; Siebert, H-C.; Cañada, F. J.; von der Lieth, C.-W.; Laynez, J.; Menéndez, M.; Bruix, M.; Soedjanaatmadja, U. M. S.; Beintema, J. J.; Gabius, H.-J.; Jiménez-Barbero, J. NMR investigation of protein-carbohydrate interactions. Structure determination of the complex between pseudohevein and N,N',N' triacetylchitotriose and delineation of two different binding modes. Proteins, 2000, 40, 218-236.

[38] Espinosa, J. F.; Asensio, J. L.; García, J.-L.; Laynez, J.; Bruix, M.; Wright, C.; Siebert, H-C.; Gabius, H.-J.; Cañada, F. J.; JiménezBarbero, J. NMR investigation of protein-carbohydrate interactions. Binding studies and refined three dimensional solution structure of the complex between the B domain of wheat germ agglutinin and N,N',N' '-triacetylchitotriose. Eur. J. Biochem., 2000, 267, 3965-3978.

[39] Koppisetty, C. A. K.; Frank, M.; Lyubartsev, A. P.; Nyholm, P.-G. Binding energy calculations for hevein-carbohydrate interactions using expanded ensemble molecular dynamics simulations. $J$. Comput. Aided Mol. Des., 2015, 29, 13-21.

[40] Battistel, M. D.; Shangold, M.; Trinh, L.; Shiloach, J.; Freedberg, D. I. Evidence for helical structure in a tetramer of alpha2-8 sialic acid: unveiling a structural antigen. J. Am. Chem. Soc., 2012, 134, 10717-10720.

[41] Schröder, J. M. Revealing the achilles heel of bacterial toxins. Immunity, 2014, 41, 671-673.

[42] Schröder, J. M.; Harder, J. Antimicrobial skin peptides and proteins. Cell. Mol. Life Sci., 2006, 63, 469-486.

[43] Böhling, A.; Hagge, S. O.; Roes, S.; Podschun, R.; Sahly, H.; Harder, J.; Schröder, J.-M.; Grötzinger, J.; Seydel, U.; Gutsmann, T. Lipid-specific membrane activity of human $\beta$-defensin-3. Biochemistry, 2006, 45, 5663-5670.

[44] Kudryashova, E.; Quintyn, R.; Seveau, S.; Lu, W.; Wysocki, V. H.; Kudryashov, D. S. Human defensins facilitate local unfolding of thermodynamically unstable regions of bacterial protein toxins. Immunity, 2014, 41, 709-721.

[45] Kudryashova, E.; Heisler, D.; Zywiec, A.; Kudryashov, D. S. Thermodynamic properties of the effector domains of MARTX toxins suggest their unfolding for translocation across the host membrane. Mol. Microbiol., 2014, 92, 1056-1071.

[46] Enani, M. A., El-Khizzi, N. A. Community acquired Klebsiella pneumoniae, K1 serotype. Invasive liver abscess with bacteremia and endophthalmitis. Saudi Med. J., 2012, 33, 782-786.

[47] Al-Saadi, M. A. K.; Al-Charrakh, A. H.; Al-Greti, S. H. H. Prevalence of bacteremia in patients with diabetes mellitus in Karbala, Iraq. J. Bacteriol., 2011, 3, 108-116.

[48] Krylov, V. B.; Argunov, D. A.; Vinnitskiy, D. Z.; Verkhnyatskaya, S. A.; Gerbst, A. G.; Ustyuzhanina, N. E.; Dmitrenok, A. S.;
Huebner, J.; Holst, O.; Siebert, H.-C.; Nifantiev, N. E. Pyranoside into furanoside rearrangement: new reaction in carbohydrate chemistry and its application in oligosaccharide synthesis. Chem. Eur. J., 2014, 20, 16516-16522.

[49] Enani, M. A.; Alharthi, B. N.; Dewanjee, N.; Bhat, N. A.; Fagih M. Spontaneous gastric ulcer perforation and acute spleen infarction caused by invasive gastric and splenic mucormycosis. J. Glob. Infect. Dis., 2014, 6, 122-124.

[50] Silva, P. M.; Gonçalves, S.; Santos, N. C. Defensins: antifungal lessons from eukaryotes Front. Microbiol., 2014, 5, 1-17.

[51] Alviano, C. S.; Travassos, L. R.; Schauer, R. Sialic acids in fungi: a minireview. Glycoconj. J., 1999, 6, 545-554.

[52] Almeida, C. A.; de Campos-Takaki, G. M.; Portela, M. B.; Travassos, L. R.; Alviano, C. S.; Alviano, D. S. Sialoglycoproteins in morphological distinct stages of mucor polymorphosporus and their influence on phagocytosis by human blood phagocytes. Mycopathologia, 2013, 176, 183-189.

[53] Tsvetkov, Y. E.; Burg-Roderfeld, M.; Loers, G.; Ard., A.; Sukhova E. V.; Khatuntseva, E. A.; Grachev, A. A.; Chizhov, A. O.; Siebert, H.-C.; Schachner, M.; Jiménez-Barbero, J.; Nifantiev, N. E. Synthesis and molecular recognition studies of the HNK-1 trisaccharide and related oligosaccharides. The specificity of monoclonal anti-HNK-1 antibodies as assessed by surface plasmon resonance and STD NMR. J. Am. Chem. Soc. 2012, 134, 426-435.

[54] Bhunia, A.; Vivekanandan, S.; Eckert, T.; Burg-Roderfeld, M. Wechselberger, R.; Romanuka, J.; Bächle, D.; Kornilov, A. V.; von der Lieth, C.-W.; Barbero, J. J.; Nifantiev, N. E.; Schachner, M. Sewald, N.; Lütteke, T.; Gabius, H.-J.; Siebert, H.-C. Why structurally different cyclic peptides can be glycomimetics of HNK-1.J. Am. Chem. Soc., 2010, 132, 96-105.

[55] Siebert, H.-C.; Lu, S.-Y.; Frank, M.; Kramer, J.; Wechselberger, R.; Joosten, J.; André, S.; Rittenhouse-Olson, K.; Roy, R., von der Lieth, C.-W.; Kaptein, R.; Vliegenthart, J. F. G.; Heck, A. J. R.; Gabius, H.-J. Analysis of protein-carbohydrate interaction at the lower size limit of the protein part (15-mer peptide) by NMR spectroscopy, electrospray ionization mass spectrometry and molecular modeling. Biochemistry, 2002, 41, 9707-9717.

[56] Siebert, H-C.; André, S.; Asensio, J. L.; Cañada, F. J.; Dong, X.; Espinosa, J. F.; Frank, M.; Gilleron, M.; Kaltner, H.; Kožár, T.; Bovin, N. V.; von der Lieth, C.-W.; Vliegenthart, J. F. G.; JiménezBarbero, J.; Gabius, H.-J. A new combined computational and NMR-spectroscopical strategy for the identification of additional conformational constraints of the bound ligand in an aprotic solvent. ChemBioChem, 2000, 1, 181-195.

[57] von der Lieth, C. W.; Siebert, H.-C.; Kožár, T.; Burchert, M.; Frank, M.; Gilleron, M.; Kaltner, H.; Kayser, G.; Tajkhorshid, E.; Bovin, N. V.; Vliegenthart, J. F. G.; Gabius, H.-J. Lectin ligands: new insights into their conformations and their dynamic behavior and the discovery of conformer selection by lectins. Acta Anat. 1998, 161, 91-109.

[58] Gilleron, M.; Siebert, H.-C.; Kaltner, H.; von der Lieth, C. W.; Kožár, T.; Halkes, K. M.; Korchagina, E. Y.; Bovin, N. V.; Gabius, H.-J.; Vliegenthart, J. F. G. Conformer selection and differential restriction of ligand mobility by a plant lectin. Conformational behaviour of Gal $\beta 1$ - 3GlcNAc $\beta 1-R$, Gal $\beta 1-3$ GalNAc $\beta 1-R$ and Gal $\beta 1$ $2 \mathrm{Gal} \beta 1-\mathrm{R}^{\prime}$ in the free state and complexed with galactoside-specific mistletoe lectin as revealed by random walk and conformational clustering molecular mechanics calculations, molecular dynamics simulations and nuclear Overhauser experiments. Eur. J. Biochem., 1998, 252, 416-427.

[59] Wu, A. M.; Singh, T.; Liu, J.-H.; Krzeminski, M.; Russwurm, R.; Siebert, H.-C.; Bonvin, A. M. J. J.; André, S.; Gabius, H.-J. Activity-structure correlations in divergent lectin-evolution: fine specificity of chicken galectin CG-14 and computational analysis of flexible ligand docking for CG- 14 and the closely related CG-16. Glycobiology, 2007, 17, 165-184.

[60] Wu, A. M.; Singh, T.; Liu, J.-H.; André, S.; Lensch, M.; Siebert, H.-C.; Krzeminski, M.; Bonvin, A. M. J. J.; Kaltner, H.; Wu, J. H.; Gabius, H.-J. Adhesion/growth-regulatory galectins: Insights into their ligand selectivity using natural glyco-proteins and glycotopes. Adv. Exp. Med. Biol., 2011, 705, 117-141.

[61] Schadow, S.; Siebert, H.-C.; Lochnit, G.; Kordelle, J.; Rickert, M.; Steinmeyer, J. Collagen metabolism of human osteoarthritic articular cartilage as modulated by bovine collagen hydrolysates. PLOS $O N E$, 2013, 8, e53955. 
[62] Stötzel, S.; Schurink, M.; Wienk, H.; Siebler, U.; Burg-Roderfeld, M.; Eckert, T.; Kulik, B.; Wechselberger, R.; Sewing, J.; Steinmeyer, J.; Oesser, S.; Boelens, R.; Siebert, H.-C. Molecular organization of various collagen fragments as revealed by atomic force microscopy and diffusion ordered NMR spectroscopy. ChemPhysChem, 2012, 13, 3117-3125.

[63] Eckert, T.; Stötzel, S.; Burg-Roderfeld, M.; Sewing, J.; Lütteke, T.; Nifantiev, N. E.; Vliegenthart, J. F. G.; Siebert, H.-C. In silico study on sulfated and non-sulfated carbohydrate chains from proteoglycans in Cnidaria and their interaction with collagen. $O . J$. Phys. Chem., 2012, 2, 123-133.

[64] Raabe, O.; Reich, C.; Wenisch, S.; Hild, A.; Burg-Roderfeld, M.; Siebert, H.-C.; Arnhold, S. Hydrolyzed fish collagen induced chondrogenic differentiation of equine adipose tissue-derived stromal cells. Histochem. Cell Biol., 2010, 134, 545-554.

[65] Siebert, H.-C.; Burg-Roderfeld, M., Eckert, T.; Stötzel, S.; Kirch, U.; Diercks, T.; Humphries, M. J.; Frank, M.; Wechselberger, R.; Tajkhorshid, E.; Oesser, S. Interaction of the $\alpha 2 \mathrm{~A}$ domain of integrin with small collagen fragments. Protein Cell, 2010, 1, 393405 .

[66] Sudheendra, U. S.; Dhople, V.; Datta, A.; Kar, R. K.; Shelburne, C. E.; Bhunia, A.; Ramamoorthy, A. Membrane disruptive antimicrobial activities of human $\beta$-defensin-3 analogs. Eur. J. Med. Chem., 2015, 91, 91-99.

[67] Santra, A.; Si, A.; Kar, R. K.; Bhunia, A.; Misra, A. K. Linear synthesis and conformational analysis of the pentasaccharide repeating unit of the cell wall O-antigen of Escherichia coli O13. Carbohydr. Res., 2014, 391, 9-15.

[68] Saravanan, R.; Joshi, M., Mohanram, H.; Bhunia, A.; Mangoni, M. L., Bhattacharjya, S. NMR structure of temporin-1 ta in lipopolysaccharide micelles: Mechanistic insight into inactivation by outer membrane. PLOS ONE, 2013, 8, e72718.

[69] Mohanran, H.; Nip, A.; Domadia, P. N.; Bhunia, A.; Bhattacharjya, S. NMR structure, localization, and vesicle fusion of Chikungunya virus fusion peptide. Biochemistry, 2012, 51, 7863-7872.

[70] Bhunia, A.; Saravanan, R.; Mohanram, H.; Mangoni, M. L.; Bhattacharjya, S. NMR structures and interactions of temporin-1Tl and temporin-1Tb with lipopolysaccharide micelles: mechanistic insights into outer membrane permeabilization and synergistic activity. J. Biol. Chem., 2011, 286, 24394-24406.

[71] Bhunia, A.; Bhattacharjya, S. Mapping residue-specific contacts of polymyxin B with lipopolysaccharide by saturation transfer difference NMR: insights into outer-membrane disruption and endotoxin neutralization. Biopolymers., 2011, 96, 273-287.

[72] Domadia, P. N.; Bhunia, A.; Ramamoorthy, A.; Bhattacharjya, S. Structure, interactions, and antibacterial activities of MSI-594 derived mutant peptide MSI-594F5A in lipopolysaccharide micelles: role of the helical hairpin conformation in outermembrane permeabilization. J. Am. Chem. Soc., 2010, 132, 18417-18428.
[73] Bhunia, A.; Domadia, P. N.; Torres, J.; Hallock, K. J.; Ramamoorthy, A.; Bhattacharjya, S. NMR structure of pardaxin, a poreforming antimicrobial peptide, in lipopolysaccharide micelles: mechanism of outer membrane permeabilization. J. Biol. Chem. 2010, 285, 3883-3895.

[74] Konno, K.; Hisada, M.; Fontana, R.; Lorenzi, C. C. B.; Naoki, H.; Itagaki, Y.; Miwa, A.; Kawai, N.; Nakata, Y.; Yasuhara, T.; Neto, J. R.; de Azevedo, W. F.; Jr., Palma, M. S.; Nakajima, T. Anoplin, a novel antimicrobial peptide from the venom of the solitary wasp Anoplius samariensis. Biochim. Biophys. Acta, 2001, 1550, 70-80.

[75] Mannis, M. J. The use of antimicrobial peptides in ophthalmology: an experimental study in corneal preservation and the management of bacterial keratitis. Tr. Am. Ophth. Soc., 2001, 99, 241-269.

[76] Peschel, A. How do bacteria resist human antimicrobial peptides? Trends Microbiol., 2002, 10, 179-186.

[77] Shankaramma, S. C.; Athanassiou, Z.; Zerbe, O.; Moehle, K.; Mouton, C.; Bernardini, F.; Vrijbloed, J. W.; Obrecht, D.; Robinson, J. A. Macrocyclic hairpin mimetics of the cationic antimicrobial peptide protegrin I: A new family of broad-spectrum antibiotics. ChemBioChem, 2002, 3, 1126-1133.

[78] D. Scheglmann, K. Werner, G. Eiselt, R. Klinger Role of paired basic residues protein C-termini phospholipid binding. Protein Eng., 2002, 15, 521-527.

[79] Asensio J. L.; Ardá A.; Cañada, F. J.; Jiménez-Barbero, J. Carbohydrate-aromatic interactions. Acc. Chem. Res., 2013, 46(4), 946954.

[80] Das, K. M.; Lee, E. Y.; Al Jawder, S. E.; Enani, M. A.; Singh, R. Skakni, L.; Al-Nakshabandi, N.; Al-Dossari, K. S.; Larsson, G. Acute Middle East Respiratory Syndrome Coronavirus: Temporal lung changes observed on the chest radiographs of 55 patients. $\mathrm{Am}$. J. Roentgenol. 2015, 205, W267-S274.

[81] Siebert, H.-C.; Zhang, R. Y.; Scheidig, A.; Eckert, T.; Wienk, H.; Boelens, R.; Mahvash, M.; Petridis, A. K.; Schauer, R. Interaction studies of sialic acids with model receptors contribute to nanomedical therapies. J. Neurol. Disord., 2015, in press.

[82] Rojas-Macias M. A.; Lütteke T. Statistical analysis of amino acids in the vicinity of carbohydrate residues performed by GlyVicinity. Methods Mol. Biol., 2015, 1273, 215-226.

[83] Hwang P. M.; Zhou N.; Shan X.; Arrowsmith C. H.; Vogel H. J. Three-dimensional solution structure of lactoferricin B, an antimicrobial peptide derived from bovine lactoferrin. Biochemistry, 1998, 37, 4288-4298.

[84] Hervé V.; Meudal H.; Labas V.; Réhault-Godbert S.; Gautron J.; Berges M.; Guyot N.; Delmas A. F.; Nys Y.; Landon C. Threedimensional NMR structure of hen egg gallin (chicken ovodefensin) reveals a new variation of the $\beta$-defensin fold. J. Biol. Chem. 2014, 289, 7211-7220. 